\title{
Mutu Pelayanan Kesehatan Di Puskesmas Baiturrahman Banda Aceh
}

\author{
Quality Control of Health Services with Patient Satisfaction in Puskesmas \\ Baiturrahman Banda Aceh
}

\author{
Fauziah Andika $^{* 1}$,Prima Hariyanto ${ }^{2}$ \\ ${ }^{1,2}$ Program Studi Ilmu Kesehatan Masyarakat, Fakultas Ilmu Kesehatan, Universitas Ubudiyah Indonesia, Banda Aceh, \\ Indonesia \\ *Korespondensi Penulis: fauziah@uui.ac.id
}

\begin{abstract}
Abstrak
Mutu pelayanan kesehatan sangat dipengaruhi oleh kualitas saran fisik, jenis tenaga yang tersedia, obat, alat kesehatan dan sarana penunjang lainnya, proses pemberian pelayanan, dan kompensasi yang diterima serta harapan masyarakat pengguna. Tujuan penelitian ini adalah untuk mengetahui hubungan mutu pelayanan perawat dengan kepuasan pasien di Puskesmas Baiturrahman, penelitian ini bersifat kuantitatif mengunakan analitik dengan desain cross sectional. Populasi dalam penelitian ini adalah seluruh masyarakat yang berkunjung di puskesmas baiturrahman, yang berjumlah 85.775 dan memakai rumus slovin di dapatkan sampel berjumlah 99 orang. Pengumpulan data ini diambil pada tanggal 06 Maret 2017. Analisa data menggunakan aplikasi computer, berdasarkan analisa Univariat didapatkan hasil kepuasan pasien puas $46(46,5 \%)$ kurang puas 53 (53,5\%),pengetahuan baik 40 (40,4\%) kurang baik $59(59,6 \%)$, akses terhadap pelayanan tersedia $33(33,3 \%)$ tidak tersedia 66 $(66,7 \%)$, fasilitas kesehatan lengkap $42(42,4 \%)$ kurang lengkap 57 (57,6\%), kenyamanan nyaman $34(34,3 \%)$ kurang nyaman $65(65,7 \%)$ dan analisa bivariat didapatkan hasil bahwa hubungan akses pelayanan kesehatan dengan kepuasan pasien di dengan $0.008<\alpha=0.05$, hubungan kepuasan pasien dengan fasilitas pelayanan dengan $0.042<\alpha=0.05$, hubungan kepuasan pasien dengan kenyamanan dengan $0.016<\alpha=0.05$, hubungan kepuasan pasien dengan pengetahuan dengan $0.015<\alpha=0.05$, atau ada hubungan antara kepuasan pasien dengan akses terhadap pelayanan, ada hubungan antara kepuasan pasien dengan fasilitas pelayanan, ada hubungan antara kepuasan pasien dengan kehandalan petugas, ada hubungan antara kepuasan pasien dengan kenyamanan, ada antara kepuasan pasien dengan pengetahuan.
\end{abstract}

Kata kunci: Kepuasan pasien, mutu pelayanan

\begin{abstract}
The quality of health services is strongly influenced by the quality of physical advice, the type of energy available, drugs, medical devices and other supporting facilities, the process of providing services, and compensation received and the expectations of the user community. The purpose of this study was to determine the relationship between the quality of nurse care
\end{abstract}


and patient satisfaction at Baiturrahman Health Center, this study was quantitative using analytical with cross sectional design. The population in this study were all people who visited the Baiturrahman Health Center, which amounted to 85,775 and used the Slovin formula to get a sample of 99 people. This data collection was taken on March 6, 2017. Analysis of the data using a computer application, based on Univariate analysis showed that the satisfaction of 46 satisfied patients (46.5\%) were less satisfied 53 (53.5\%), good knowledge 40 (40.4\%) not good 59 (59.6\%), access to services available 33 (33.3\%) not available 66 (66.7\%), complete health facilities 42 (42.4\%) incomplete 57 (57.6\%) comfortable comfort 34 (34.3\%) less comfortable 65 (65.7\%) and Bivariate analysis showed that the relationship of access to health services with patient satisfaction with $0.008<\alpha=$ 0.05 , relationship between patient satisfaction and service facilities with $0.042<\alpha=0.05$, the relationship between patient satisfaction and comfort with $0.016<\alpha=0.05$, the relationship between patient satisfaction and knowledge with $0.015<\alpha=0.05$, or there is a relationship between patient satisfaction and access to services, there is a relationship between patient satisfaction and service facilities, there is a relationship between patient satisfaction with the reliability of officers, there is the relationship between patient satisfaction and comfort, there is between patient satisfaction and knowledge.

Keywords: Patient satisfaction, service quality

\section{PENDAHULUAN}

Mutu pelayanan kesehatan sangat dipengaruhi oleh kualitas saran fisik, jenis tenaga yang tersedia, obat, alat kesehatan dan sarana penunjang lainnya, proses pemberian pelayanan, dan kompensasi yang diterima serta harapan masyarakat pengguna. Berbagai upaya telah dilakukan untuk meningkatkan mutu dan kinerja pelayanan, agar pelayanan kesehatan memberi jaminan keamanan dan kepuasan kepada pasien dan masyarakat pengguna (Daldiyono Hardjodisastro, 2011).

Satu-satunya Negara maju yang tidak memiliki pelayanan kesehatan universal adalah Amerika Serikat. Tetapi pada 21 maret 2013 House Of Reflesentatives (Dewan Perwakilan Rakyat) AS mengesahkan RUU Reformasi Kesehatan yang diusulkan Barack Obama dan Partai Demokrat. Dengan Undang-undang itu AS akan mengimplementasikan pelayanan kesehatan universal mulai tahun 2014 dengan menggunakan sisitem mandate asuransi. Mexiko, Afrika Selatan, Thailand, dan Indonesia, merupakan beberapa diantara Negara yang sedang mencoba mengimplementasikan pelayanan kesehatan universal.indonesia merupakan salah satu Negara yang sedang dalam masa transisi menuju system pelayanan kesehatan universal. Undang-undang sisitem jaminan sosial Nasional mewajibkan setiap warga diindonesia memiliki akses pelayanan kesehatan komprehensif yang dibutuhkan melalui system pra-upaya (Hafizurrachman, 2015). 
Kepemilikan jaminan kesehatan penduduk menurut provinsi sangat bervariasi. Provinsi Aceh menjadi provinsi yang paling tinggi cakupan kepemilikan jaminan diantara provinsi lain, yaitu sekitar 96,6 \% penduduk atau hanya 3,4 \% yang tidak punya jaminan apapun. Sebaliknya DKI Jakarta menjadi provinsi dengan cakupan kepemilikan jaminan kesehatan yang paling rendah dengan 69,1 \% penduduk tidak punya jaminan (Riskesdas, 2013).

Puskesmas Baiturrahman Kecamatan Baiturrahman mempunyai 1 Puskesmas induk yaitu Puskesmas Baiturrahman, pada tahun 2016 jumlah kunjungan pasien sebanyak 85.775 orang pada bulan Januari berjumlah 7.940 (7.8\%) kunjungan, Februari 10.290 (10.2\%) kunjungan, Maret 16.626 (19.2\%) kunjungan, April 10.680 (10.3\%) kunjungan, Mei 8.759 (7.7\%) kunjungan, Juni 4.497 (6.7\%) kunjungan, Juli 3.372 (5.2\%) Kunjungan, Agustus 5.912 (6.9\%) kunjungan, September 5.021 (6.9\%) kunjungan, Oktober 4.687 (3.2\%) Kunjungan, November 4.836 (3.9\%) kunjungan, Desember 3.155 (4.0\%) kunjungan dan bulan Januari 20172.342 kunjungan.

\section{METODE PENELITIAN}

Jenis penelitian ini bersifat Survey Analitik dengan desain cross sectional. Populasi dalam penelitian ini adalah seluruh pasien yang berkunjung Puskesmas Baiturrahman Banda Aceh yang berjumlah 85.775 pasien pada tahun 2016 sampai Januari 2017, sampel penelitian ini berjumlah 99 pasien yang dilakukan pada tanggal 06 Maret s.d 12 Maret 2017 yang dibantu dengan enumerator. Data diolah dengan uji Chi-Square dan menggunakan komputerisasi dengan CI (Confident Interval) 95\%.

\section{HASIL DAN PEMBAHASAN}

Tabel 1. Hubungan Akses Pelayanan, Fasilitas Pelayanan Kesehatan dan Kenyamanan dengan Kepuasan Pasien

\begin{tabular}{|c|c|c|c|c|c|c|}
\hline \multirow{3}{*}{ No } & \multirow{3}{*}{ Variabel } & \multicolumn{4}{|c|}{ Kepuasaan } & \multirow{3}{*}{$P$ value } \\
\hline & & \multicolumn{2}{|c|}{ Kurang Puas } & \multicolumn{2}{|c|}{ Puas } & \\
\hline & & $\mathbf{n}$ & $\%$ & $\mathbf{n}$ & $\%$ & \\
\hline \multirow{3}{*}{1} & Akses terhadap pelayanan & & & & & \multirow{3}{*}{0.008} \\
\hline & a. tidak tersedia & 42 & 63.6 & 24 & 36.4 & \\
\hline & b. Tersedia & 11 & 33.3 & 22 & 66.7 & \\
\hline \multirow{3}{*}{2} & Fasilitas Pelayanan Kesehatan & & & & & \multirow{3}{*}{0.042} \\
\hline & a. Kurang Lengkap & 36 & 63.2 & 21 & 36.8 & \\
\hline & b. Lengkap & 17 & 40.5 & 25 & 59.5 & \\
\hline
\end{tabular}


Kenyamanan

\begin{tabular}{|c|c|c|c|c|c|}
\hline a. Kurang Nyaman & 41 & 63.1 & 24 & 36.9 & 0.055 \\
\hline b. Nyaman & 12 & 35.3 & 22 & 64.7 & \\
\hline
\end{tabular}

\section{Pembahasan}

\section{Hubungan Akses Terhadap Pelayanan dengan Kepuasan Pasien}

Dari Tabel 1 diketahuidari 33 responden dengan akses terhadap pelayanan tersedia dan kepuasan pasien dikategorikan kurang puas berjumlah 11 (33.3\%) responden dan kepuasan pasien dikategorikan puas berjumlah 22 (66.7\%) responden. Selanjutnya dari 66 responden dengan akses terhadap pelayanan tidak tersedia dan kepuasan pasien dikategorikan kurang puas berjumlah 42 (63.6\%) responden dan kepuasan pasien dikategorikan puas berjumlah 24 (36.4\%) responden. Berdasarkanujistatistikdengannilai $P$ Value $=0,008$ adahubunganantarakepuasan pasien dengan akses terhadap pelayanan kesehatan di Puskesmas Baiturrahman Banda Aceh Tahun 2017.

Penelitian ini sejalan dengan penelitian (Sri Hartani, 2012) yaitu Lokasi meliputi letak puskesmas, tarif, sarana dan prasarana, dan motivasi pasien. Merupakan beberapa aspek yang menentukan pertimbangan dalam memilih rumah puskesmas. Umumnya semakin dekat tempat pelayanan dengan pusat perkotaan atau yang mudah dijangkau, mudahnya transfortasi dan lingkungan yang baik akan menjadi pilihan bagi pasien yang membutuhkan rumah sakit tersebut. Kemudahan mendapat pelayanan atau produk yang diatawrkan produsen juga menjadi faktor penting yang mempengaruhi kepuasan pelanggan. Pelanggan akan merasa puas bila mereka dapat dengan mudah mengakses produk/ pelayanan jasa yang dibutuhkan. Kemampuan akses ini bisa diartikan tersedianya fasilitas yang mudah, terjangkau dari segi jarak, dan terjangkau dari segi biaya dan lainlain.

Peneliti berasumsi bahwa ada hubungan antara kepuasan pasien dengan akses terhadap pelayanan, ini dikarenakan dengan adanya akses yang mudah terhadap pelayanan maka memudahkan pula bagi masyarakat untuk melakukan kunjungan ke puskesmas tersebut untuk mendapatkan pelayana kesehatan yang optimal, tetapi sebaliknya apabila akses terhadap pelayanan tidak tersedia dengan baik maka akan berdampak pada jumlah kunjungan pasien ke puskesmas tersebut 
2. Hubungan Fasilitas Pelayanan dengan Kepuasan Pasien

Dari Tabel 1 diketahui dari 42 responden dengan fasilitas pelayanan kesehatan lengkap dan kepuasan pasien dikategorikan kurang puas berjumlah 17 (40.5\%) responden dan kepuasan pasien dikategorikan puas berjumlah 25 (59.5\%) responden. Selanjutnya dari 57 responden dengan fasilitas pelayanan kesehatan kurang lengkap dan kepuasan pasien dikategorikan kurang puas berjumlah 36 (63.2\%) responden dan kepuasan pasien dikategorikan puas berjumlah 21 (36.8\%) responden. Berdasarkanujistatistikdengannilai $P$ Value $=0,042$ ada hubungan antara kepuasan pasien dengan fasilitas kesehatan di Puskesmas Baiturrahman Banda Aceh Tahun 2017.

Penelitian ini sejalan dengan teori yang dikemukankan oleh Rosmawati (2012) yaitu Puskesmas adalah tempat dimana masyarakat mula melakukan pengobatan, jumlah kunjungan di sebuah puskesmas biasanya dipengaruhi oleh beberapa faktor yaitu fasilitas pelayanan, kenyamanan, dan akses. Apabila ketiga faktor tersebut tidak mendukung di dalam berjalannya sebuah instalasi kesehatan maka jumlah kunjungan di puskesmas tersebut akan berkurang, masyarakat lebih memilih pengobatan alternatif ketimbang pengobatan di puskesmas.

Pembangunan di bidang kesehatan bertujuan agar semua lapisan masyarakat dapat memperoleh pelayanan kesehatan secara merata dan muarah. Dengan tujuan tersebut diharapkan akan meningkatkan derajat kesehatan masyarakat. Selain itu, pembangunan kesehatan juga memuat mutu dan upaya kesehatan yang sangat dipengaruhi oleh ketersdiaan fasilitas kesehatan dengan menciptakan akses pelayanan dasar yang didukung oleh sumber daya yang memadai seperti Rumah Sakit, Puskesmas, Klinik, dan Praktek Dokter. Untuk menimbulkan kepuasan pasien terhadap pelayanan kesehatan, banyak cara yang harus dipenuhi. Salah satu diantaranya yang dinilai mempunyai peranan yang cukup penting adalah ketersediaan fasilitas kesehatan, maka sering disebut suatu pelayanan kesehatan adalah pelayanan kesehatan yang bermutu apabila tersedianya fasilitas kesehatan (Rosmawati, 2012).

Peneliti berasumsi bahwa ada hubungan antara kepuasan pasien dengan fasilitas pelayanan kesehatan yang ada di puskesmas, ini dikarenakan apabila sebuah puskesmas tidak memiliki fasilitas yang memadai terhadap pelayan kesehatan/ penunjang kesehatan maka masyarakat enggan untuk melakukan pengobatan pada puskesmas tersebut. 
Sehingga jumlah kunjungan pada puskesmas tersebut sedikit, masyarakat akan lebih memiih pengobatan alternatif dibandingkan pengobatan yang dilkaukan di puskesmas.

3. Hubungan Kepuasan Pasien Dengan Kenyamanan

Dari Tabel 1 diketahui dari 34 responden dengan kenyamanan dikategorikan nyaman dan kepuasan pasien kurang puas berjumlah 12 (35.3\%) responden dan kepuasan pasien puas berjumlah $22(64.7 \%)$ responden. Selanjutnya dari 65 responden dengan kenyamann dikategorikan kurang nyaman dan kepuasan pasien kurang puas berjumlah 41 (63.1\%) responden dan kepuasn pasien puas berjumlah 24 (36.9\%) responden. Berdasarkan uji statistic dengan nilai $P$-Value $=0,016$ ada hubungan antara kepuasan pasien dengan kenyamanan di Puskesmas Baiturrahman Banda Aceh Tahun 2017.

Penelitian ini sejalan dengan penelitian Asti (2013) yaitu Kenyamanan adalah suatu keadaan yang dapat mempengaruhi seseorang dalam melakukan dan melaksanakan pekerjaan dan mengikuti suatu arahan yang diberikan untuk mencapai tujuan. Selain itu faktor SDM dan sarana dan prasarana juga menjadi titik temu hubungan pada kunjungan pasien ke puskesmas. Para professional, khususnya dokter-dokter medis, pada tingkat tertentu juga spikolog, telah belajar untuk mengkonseptualisasikan kesehatan dan kesakitan didasarkan atas standar ilmiah.

Peneliti berasumsi bahwa ada hubungan kepuasan pasien dengan kenyamanan, karena dengan pasien nyaman maka pasien betah berlama-lama di puskesmas, dan apabila menunggu antrian mereka mampu menunggu, tetapi kenyamanan dalam melakukan pengobatan dimana dokter memberikan kenyamanan yang semaksimal mungkin sehingga masyarakat/pasien tidak merasa risih atau canggung dalam melakukan pengobatan.

4. Hubungan Pengetahuan dengan Kepuasan Pasien

Dari Tabel 1 diketahui dari 40 responden dengan pengetahuan baik dan kepuasan pasien kurang puas berjumlah 15 (37.5\%) responden dan kepuasan pasien puas berjumlah $25(62.5 \%)$ responden. Selanjutnya dari 59 responden dengan pengetahuan kurang baik dan kepuasan pasien kurang puas berjumlah 38 (64.4\%) responden dan kepuasan pasien puas berjumlah $21(35.6 \%)$ responden. Berdasarkan uji statistic dengan nilai $P$-Value $=$ 0,015 ada hubungan antara kepuasan pasien dengan pengetahuan di Puskesmas Baiturrahman Banda Aceh Tahun 2017. 
Penelitian ini sejalan dengan teori yang dikemukakan oleh Sri Hartani (2012) Pengetahuan petugas rumah sakit menentukan kualitas atau mutu pelayanan rumah sakit itu sendiri, ini dikarenakan apabila seorang perawat tidak memiliki pengetahuan yang matang akan ilmu perawat maka ia akan mengabaikan pekerjaan-pekerjaan sepele yang oleh pasien itu adalah pekerjaan penting, contohnya terkadang ketika jam istirahat tetapi pasien masih banyak perawat sering mengabaikan pasien, tetapi apabila pengetahuan perawat matang maka perawat akan memberlakukan system shif kerja sehingga pelayanan kesehatan yang ada di rumah sakit atau instalasi berjalan dengan baik.

Peneliti berasumsi bahwa ada hubungan antara pengetahuan dengan kepuasan pasien di puskesmas, karena dengan adanya pengetahuan yang memadai tentang ilmu kesehatan pada petugas maka pasien akan merasa yakin akan kesembuhan yang sedang ia alami, dan begitu juga pada masyarakat, ketika masyarakat memiliki pengetahuan yang baik maka ia akan melakukan pengobatan kesehatan ke puskesmas sebaliknya apabila masyarakat tidak memiliki pengetahuan yang baik maka ia akan mencari pengobatan alternatif lain yang jauh dengan bidangnya (misalnya dukun).

\section{KESIMPULAN}

Dari penelitian ini dapat disimpulkan bahwa ada hubungan antara fasilitas pelayanan,kenyamanan,kehandalan petugas, akses terhadap pelayanan dan pengetahuan dengan kepuasan pasien dengan nilai $p$-value $<0,05$.

\section{SARAN}

Diharapkan kepada pihak puskesmas agar lebih mengedepankan kepuasan masyarakat dalam melakukan pengobatan di puskesmas tersebut, karena apabila masyarakat tidak puas dengan pelayanan kesehatan yang diberikan oleh puskesmas tersebut maka kunjungan masyarakat pada puskesmas tersebut akan menurun dan apabila terus berlanjut kemungkinan besar tidak ada lagi masyarakat yang melakukan pengobatan di puskesmas tersebut, kemudian apabila akses terhadap pelayanan tidak berjalan dengan baik maka masyarakat akan merasa kewalahan dengan akses, contohnya apabila jalan rusak atau jauh,dan juga tidak ada juga kendaraan umum yang melewati jalan puskesmas tersebut sehingga masyarakat tidak akan mengunjungi puskesmas tersebut dan lebih memilih pengobatan alternative lain. 


\section{DAFTAR PUSTAKA}

Hamidiyah, Azizatul., (2013). Hubungan Persepsi Pasien tentang Kualitas Pelayanan dengan Minat Kunjungan Ulang Di Klinik Umum rumah Sakit Bhineka Bakti Husada Kota Tanggerang Selatan Tahun 2013. Jurnal.

Hartini, Sri., (2012). Pengaruh Tarif Rawat Inap, Kualitas Pelayanan Dan Promosi Terhadap Kepuasan Pasien Di RSU Jati Husada Karanganyar. Jurnal.

Hardjodisastro, Daldiyono., (2011). Menuju Seni Ilmu Kedokteran. Jakarta : PT Gramedia Pustaka Utama

Jahid, Halimah., (2013). Faktor Yang Berhubungan Dengan Kepuasan Pasien Peserta Jamkesmas Pada Ruang Rawat Inap Di Rumah Sakit Elim Rantepao Kabupaten Toraja Utara. Jurnal.

Khairani, Laila., (2011). Faktor-Faktor Yang Mempengaruhi kepuasa Pasien Rawat Jalan RSUD Pasaman Barat. Jurnal.

Karyati, Sri Berdi., (2006). Analisis Pengaruh Persepsi Pasien Tentang Mutu Pelayanan Dokter Spesialis Obstetri Dan Ginekologi Dengan Minat Kunjungan Ulang Pasien Di Instalasi Rawat Jalan RSI Sultan Agung Semarang Tahun 2006. Jurnal.

Mubin, Lia Farihul., (2012). Prediksi Jumlah Kunjungan Pasien Rawat Jalan Menggunakan Metode Genetic Fuzzy Systems studi kasus : Rumah Sakit Usada Sidoarjo. Jurnal.

Nonutu, Prissy Thalia., (2015). Hubungan Jumlah Kunjungan Pasien Dengan Ketepatan Pelaksanaan Triase Di Instalasi Gawat Darurat RSUP Prof.Dr.R. Kandou Manado. Jurnal.

Nurlianti, Dewi., (2014). Hubungan Antara Kualitas Pelayanan Dengan Kepuasan Pasien Di Ruang Rawat Inap Anak Rumah Sakit Umum Daerah Pantura M.A Sentot Patrol Kabupaten Indramayu Tahun 2014. Jurnal.

Rosmawati. (2012). Pengaruh Kualitas Pelayanan Jasa Terhadap Loyalitas Pasien Di Rumah Sakit Bhakti Kartini. Jurnal.

Wilantara, Irchas Eko., (2015). Analisis Kepuasan Pasien Peserta BPJS Kesehatan Pada Pelayanan Rawat Jalan Tingkat Pertama (RJTP) Di Kota Banda Lampung. Jurnal. 